\title{
EDITORIAL
}

\section{IMPROVING CARE FOR COMMUNITY DWELLING FRAIL ELDERS THROUGH PATIENT AND PROVIDER ENGAGEMENT}

\author{
S. STUDENSKI
}

Director, Longitudinal Studies Section, Intramural Program, National Institute on Aging, Baltimore MD 21225, USA, Email: studenskisa@mail.nih.gov, Phone: 410 350 3964

Effective health care for older adults must attend to not only proper prevention and management of acute and chronic disease, but also to the unique health-related problems of late life. Health and functional difficulties in late life are characterized by multiple interacting age-related alterations in cells and organ systems. Often described within the conceptual framework of "frailty", these complex health problems demand a new approach from the health care system that involves recognition, evaluation and management by a multidisciplinary team. Such multidisciplinary approaches are often categorized within the rubric of geriatric evaluation and management teams or "GEMS".

Over the last decades, an evidence base for the effectiveness of GEMS has emerged. Much of this evidence is based on screening of hospital inpatients for those at high risk, while a smaller evidence base exists for purely outpatient- based approaches. Recent meta- analyses and summaries suggest, at best, modest and time-limited effects on survival, functional status, health care use and other important outcomes (1-9). Several important challenges that may contribute to limited program effectiveness, especially for outpatient programs, include engagement of primary care providers, convenient and accurate screening approaches to yield efficient targeting of high risk individuals, and capacity to implement management recommendations (10-15). In addition, the actual content of assessments has varied widely, as have the balance of medical, social and functional issues addressed by the process.

The Geriatric Frailty Clinic at the Gerontopole, described in this issue of JNHA (16), confronts these key issues in innovative ways. Most impressive is the engagement of primary care providers and regional health authorities. Primary care providers appear to be able to identify and refer patients using a convenient, brief screening tool integrated with the provider's clinical judgment. This approach to screening appears to result in a referred population who resemble the target population of persons with clear vulnerability to disability but low rates of established serious disability. The intervention appears to incorporate a range of medical, functional, social and behavioral issues. While adherence rates are not yet reported, the approach prioritizes efforts to keep primary providers and patients involved and thus to enhance ongoing interest in the recommendations. Thus Gerontopole has addressed several major challenges of feasibility: primary provider education and involvement, efficient and acceptable screening that yields a target population for services, a reasonable mix of medical, social and functional interventions and strong attention to adherence through ongoing communication with patients and providers.

This work to establish feasibility and to operationalize procedures is essential prior to the next important step; to evaluate effectiveness. The design of evaluation trials should focus on generalizable models of patient-centered care and on comparative effectiveness rather than on pure efficacy, perhaps along the models of PCORI in the US (17). To achieve this generalizable result, such a future multisite study will need to develop reproducible outreach plans for providers, patients and families; guidelines for care processes; consensus on key predictor and outcome factors; and complex plans for data management and analysis.

The work accomplished here is an important step toward the universal goal of advocates for the aging; future enthusiastic support by providers and health authorities for a change in approach to the care of vulnerable frail older adults. It's been decades, but perhaps we are now on the right track.

Acknowledgements: none

COIs: none

\section{References}

1. Cohen HJ, Feussner JR, Weinberger M, et al. A controlled trial of inpatient and outpatient geriatric evaluation and management. The New England journal of medicine 2002;346:905-12.

2. Counsell SR, Callahan CM, Clark DO, et al. Geriatric care management for lowincome seniors: a randomized controlled trial. JAMA : the journal of the American Medical Association 2007;298:2623-33.

3. Deschodt M, Flamaing J, Haentjens P, Boonen S, Milisen K. Impact of geriatric consultation teams on clinical outcome in acute hospitals: a systematic review and meta-analysis. BMC medicine 2013;11:48.

4. Ellis G, Whitehead MA, O'Neill D, Langhorne P, Robinson D. Comprehensive geriatric assessment for older adults admitted to hospital. The Cochrane database of systematic reviews 2011:CD006211.

5. Kuo HK, Scandrett KG, Dave J, Mitchell SL. The influence of outpatient comprehensive geriatric assessment on survival: a meta-analysis. Archives of gerontology and geriatrics 2004;39:245-54.

6. Leveille SG, Wagner EH, Davis C, et al. Preventing disability and managing chronic illness in frail older adults: a randomized trial of a community-based partnership with primary care. Journal of the American Geriatrics Society 1998;46:1191-8.

7. Li CM, Chen CY, Li CY, Wang WD, Wu SC. The effectiveness of a comprehensive geriatric assessment intervention program for frailty in community-dwelling older people: a randomized, controlled trial. Archives of gerontology and geriatrics 2010;50 Suppl 1:S39-42.

8. Phelan EA, Balderson B, Levine M, et al. Delivering effective primary care to older adults: a randomized, controlled trial of the senior resource team at group health cooperative. Journal of the American Geriatrics Society 2007;55:1748-56. 


\section{IMPROVING CARE FOR COMMUNITY DWELLING FRAIL ELDERS THROUGH PATIENT AND PROVIDER ENGAGEMENT}

9. Van Craen K, Braes T, Wellens N, et al. The effectiveness of inpatient geriatric evaluation and management units: a systematic review and meta-analysis. Journal of the American Geriatrics Society 2010;58:83-92.

10. Fairhall N, Langron C, Sherrington C, et al. Treating frailty--a practical guide. BMC medicine 2011;9:83

11. Hoogendijk EO, van der Horst HE, Deeg DJ, et al. The identification of frail older adults in primary care: comparing the accuracy of five simple instruments. Age and ageing 2013;42:262-5

12. Jahnigen DW, Applegate WB, Cohen HJ, et al. Working group recommendations: research on content and efficacy of geriatric evaluation and management interventions. Journal of the American Geriatrics Society 1991;39:42S-4S.

13. Kramer A, Deyo R, Applegate W, Meehan S. Research strategies for geriatric evaluation and management: conference summary and recommendations. Journal of the American Geriatrics Society 1991;39:53S-7S
14. Lacas A, Rockwood K. Frailty in primary care: a review of its conceptualization and implications for practice. BMC medicine 2012;10:4.

15. Pialoux T, Goyard J, Lesourd B. Screening tools for frailty in primary health care: a systematic review. Geriatrics \& gerontology international 2012;12:189-97.

16. Tavassoli N GS, Abellan Van Kan G, Sourdet S et al. Description of 1108 Older Patients Referred by their Physicians to the "Geriatric Frailty Clinic (GFC) for Assessment of Frailty and Prevention of Disability" at the Gerontopole. J Nutr Health Aging 2014;18(4):457-464

17. Selby JV, Lipstein SH. PCORI at 3 years--progress, lessons, and plans. The New England journal of medicine 2014;370:592-5. 